\title{
Are Compounds Membrane-Associated or Present in the Cytosol? A Study Using Polyphenols in a Colon Carcinoma Cell Line Model
}

\author{
Hannah Deusser $^{1} \cdot$ Isabel Groh $^{2} \cdot$ Tamara Bakuradze $^{1} \cdot$ Nadine Simson $^{1} \cdot$ Eva Kaiser $^{3} \cdot$ Holger Barth $^{3} \cdot$ Elke Richling $^{1}$
}

Accepted: 27 September 2020 / Published online: 16 October 2020

(C) The Author(s) 2020

\begin{abstract}
Purpose We investigated the cytosolic and membrane-associated contents of polyphenols after 4 hours of incubation $(50 \mu \mathrm{M}$ of each polyphenol) in the colon carcinoma cell line T84 using a novel, rapid, and convenient method based on permeabilization of the cell membrane using digitonin. The colon carcinoma cell line was used to investigate the intestinal uptake of polyphenols present in apple products.

Recent Findings The results showed that hydroxycinnamic acids (caffeic and 5-caffeoylquinic acid) were only detected in the cytosolic fractions. In contrast, 0.3 to $8.2 \%$ of the initial concentrations $(50 \mu \mathrm{M})$ of the flavonoids phloretin, quercetin, phloretin $2^{\prime}$ - $O$-glucoside, and quercetin 3-O-rhamnoside were found in the membrane-associated fractions. In the cytosolic fractions, $0.2-$ $2.9 \%$ of these compounds were detected, corresponding to 25 to $40 \%$ of the total cell-associated (cytosolic plus membraneassociated fractions) polyphenol content.

Summary Our results showed that after uptake, polyphenols were present in the cytosolic fraction of the cells as well as associated with the cell membrane. The presented method provides a useful in vitro tool for determining biologically active compounds in cellular fractions.
\end{abstract}

Keywords Intracellular $\cdot$ Cytosol $\cdot$ Membrane $\cdot$ Digitonin $\cdot$ Polyphenols $\cdot$ Uptake $\cdot$ Colonic cells

$\begin{array}{ll}\text { Abbreviations } & \\ \text { DMEM } & \text { Dulbecco's Modified Eagle's Medium } \\ \text { DMSO } & \text { Dimethyl sulfoxide } \\ \text { EEA } & \text { Early endosome antigen 1 } \\ \text { FCS } & \text { Fetal calf serum } \\ \text { Hsp90 } & \text { Heat shock protein } 90 \\ \text { HPLC-DAD } & \begin{array}{l}\text { High-performance liquid } \\ \text { chromatography-diode array detection }\end{array} \\ \text { LODs, } & \text { Limits of detection }\end{array}$

This article is part of the Topical Collection on Redox Modulators

Elke Richling

richling@chemie.uni-kl.de

1 Department of Chemistry, Division of Food Chemistry and Toxicology, Technische Universität Kaiserslautern, Erwin-Schrödinger-Str. 52, 67663 Kaiserslautern, Germany

2 Institute of Experimental and Clinical Pharmacology and Toxicology, University of Tübingen, Wilhelmstraße 56, 72074 Tübingen, Germany

3 Institute of Pharmacology and Toxicology, University of Ulm Medical Center, Albert-Einstein-Allee 11, 89081 Ulm, Germany

\begin{tabular}{|c|c|}
\hline LOQs & Limits of quantitation \\
\hline SDS-PAGE & $\begin{array}{l}\text { Sodium dodecyl sulfate } \\
\text { polyacrylamide gel electrophoresis }\end{array}$ \\
\hline $\mathrm{S} / \mathrm{N}$ & Signal to noise \\
\hline
\end{tabular}

\section{Introduction}

Polyphenols are secondary plant compounds frequently ingested in our daily diet. Fruits, vegetables, cereals, chocolate, and drinks (e.g., tea, wine, coffee, and fruit juices) are the major sources of polyphenols [1,2]. Apples (Malus domestica Borkh.) contain between 5.2 and $27.2 \mathrm{~g} / \mathrm{kg}$ dry weight polyphenols of various classes (hydroxycinnamic acids, dihydrochalcones, flavonols, and flavan-3-ols) [3]. Consuming apples can have several positive effects on human health, e.g., by reducing the risk of lung cancer, colorectal cancer, diabetes, cardiovascular diseases, and asthma $[4,5]$. To assess their anti-cancer roles, various groups have investigated the absorption of polyphenols (hydroxycinnamic acids and flavonoids) by colonic carcinoma cell lines. After incubation with polyphenols, up to $1.6 \%$ of applied amounts were 
found within such cells after homogenization and quantitative analysis [6-14]. However, differences between the cytosolic content and compounds associated with the cell membrane were not distinguished $[6,7,11,12]$. In one study, two fractions, one cytosolic and one membrane-associated, were separated using a method that was time-consuming and laborious [7].

The aim of the present study was to determine the cytosolic and membrane-associated polyphenol contents of a colon carcinoma cell line, T84, after incubation with polyphenols present in apples, i.e., caffeic acid, 5-caffeoylquinic acid, phloretin, phloretin $2^{\prime}$-O-glucoside, quercetin, and quercetin 3-Orhamnoside (for structures, see Fig. 1). The cells were permeabilized according to Kaiser et al. [15] by incubating them with digitonin, a saponin glycoside with hemolytic properties. Then, supernatants (cytosolic fractions) containing the cytosolic polyphenols were analyzed by high-performance liquid chromatography-diode array detection (HPLC-DAD). Furthermore, the polyphenol content of membrane-associated fractions, obtained after subsequent lysis of the cells, was determined by HPLC-DAD as well. Additionally, to check whether separation of the cytosolic fraction from the remaining membrane-associated fraction was successful, the early endosome antigen 1 (EEA1) was determined via western blot analysis. EEA1 is a marker protein for early endosomal vesicles [16], usually found solely in membrane fractions but not in cytosol.

\section{Materials and Methods}

\section{Chemicals}

All chemicals and solvents were of analytical grade. DMEM/Ham's F12 (1:1) cell culture medium, bovine liver catalase, caffeic acid, 5-caffeoylquinic acid, phloretin, phloretin 2'$O$-glucoside, 3,4,5-trimethoxycinnamic acid, digitonin, and Hanks' balanced salt solution (HBSS) were obtained from Sigma-Aldrich (Steinheim, Germany). Cell culture supplements

Fig. 1 Structures of apple polyphenols used in the study<smiles>O=C(O)/C=C/c1ccc(O)c(O)c1</smiles>

caffeic acid<smiles>O=C(/C=C/c1ccc(O)c(O)c1)OC1C[C@](O)(C(=O)O)C[C@H](O)[C@H]1O</smiles>

5-caffeoylquinic acid were all obtained from Invitrogen (Darmstadt, Germany), quercetin from Merck (Darmstadt, Germany), and quercetin 3-Orhamnoside from Roth (Karlsruhe, Germany). Methanol was purchased from J.T. Baker (Deventer, the Netherlands) and formic acid from chemsolute (Renningen, Germany). Stock solutions of each polyphenol in DMSO (Merck, Darmstadt, Germany) were prepared with a concentration of $100 \mathrm{mM}$. Digitonin was dissolved in PBS to a concentration of $20 \mu \mathrm{g} / \mathrm{mL}$.

\section{Cell Culture}

A human colonic epithelial cell line derived from a lung metastasis of colon carcinoma, T84 (CCL-248), was obtained from the American Type Culture Collection (Rockville, MD, USA). The cells were grown in a humidified incubator $\left(5 \% \mathrm{CO}_{2}, 37^{\circ} \mathrm{C}\right)$ in $75 \mathrm{~cm}^{2}$ flasks in DMEM/Ham's F12 (1:1) medium supplemented with $10 \%$ FCS, 100 units/mL penicillin, $100 \mu \mathrm{g} / \mathrm{mL}$ streptomycin, and $2 \mathrm{mM}$ L-glutamine and then seeded in six-well plates at $1 \times 10^{6}$ cells with $2 \mathrm{~mL}$ fresh medium per well. Caco- 2 cells were obtained from Deutsche Sammlung von Mikroorganismen und Zellkulturen GmbH (DSMZ) (Braunschweig, Germany). DMEM/Ham's F12 (1:1) $(\times 1)$ medium with 15 mM HEPES and L-glutamine, fetal calf serum (FCS), penicillin/streptomycin, and molecular protein marker SeeBlue Plus2 were purchased from Invitrogen $\mathrm{GmbH}$ (Karlsruhe, Germany). The monoclonal anti-Hsp90 antibody was purchased from Santa Cruz Biotechnology (Heidelberg, Germany), whereas the polyclonal anti-endosomal protein EEA1 antibody was obtained from Novus Biologicals (Littleton, USA).

\section{Incubation}

Forty-eight hours after seeding, $2 \mathrm{~mL}$ of HBSS containing 200 units catalase was added to each well together with $1.0 \mu \mathrm{L}$ of polyphenol stock solution (to separate wells, in duplicate) to achieve an initial concentration in the incubation mixture of $50 \mu \mathrm{M}$. The plates were then returned to the<smiles>O=C(CCc1ccc(O)cc1)c1c(O)cc(O)cc1O</smiles><smiles>O=c1c(O)c(-c2ccc(O)c(O)c2)oc2cc(O)cc(O)c12</smiles><smiles>O=C(CCc1ccc(O)cc1)c1c(O)cc(O)cc1O[C@@H]1O[C@H](CO)[C@@H](O)[C@H](O)[C@H]1O</smiles><smiles>C[C@@H]1OC(Oc2c(-c3ccc(O)c(O)c3)oc3cc(O)cc(O)c3c2=O)[C@H](O)[C@@H](O)C1O</smiles>

quercetin 3-O-rhamnoside 
incubator for an additional $4 \mathrm{~h}$. The cells in one of the wells for each polyphenol were then lysed with $1 \mathrm{~mL}$ TriFast reagent (Peqlab, Erlangen, Germany) for $15 \mathrm{~min}$ at room temperature. Obtained cell suspensions were scraped from the wells and stored at $-24{ }^{\circ} \mathrm{C}$ until analysis. The cells in the other wells were washed twice with ice-cold PBS $(1 \mathrm{~mL})$ and then incubated (using a method adapted from Kaiser et al. [15]) with $1-\mathrm{mL}$ digitonin solution for $5 \mathrm{~min}$ at room temperature to permeabilize the cell membrane, followed by $30 \mathrm{~min}$ on ice to release analytes from the cytosol (cytosolic fraction). The supernatant in each of these wells was collected and stored at $24{ }^{\circ} \mathrm{C}$ until analysis. To obtain the membrane-associated fractions, the digitonin-treated cells were lysed with TriFast reagent and stored as described above. Washing twice with PBS was considered sufficient because HPLC-DAD analysis of solution removed after the second washing showed that it contained no polyphenols. All experiments were conducted in triplicate.

\section{Sample Preparation and HPLC-DAD Analysis}

According to Bergmann et al. [17], cell suspensions were thawed in a sonication bath for $20 \mathrm{~min}$, and then $200-\mu \mathrm{L}$ aliquots of the cell suspensions were passed through a $3 \mathrm{kDa}$ membrane (Nanosep $3 \mathrm{~K}$ Omega from Pall, Michigan, USA) by centrifugation $\left(10,600 \times g, 4{ }^{\circ} \mathrm{C}, 5 \mathrm{~min}\right)$ until dry, which correspond to the total cell-associated fractions. The membrane was then washed once with $100 \mu \mathrm{L}$ and twice with $50-\mu \mathrm{L}$ formic acid in methanol $(10 / 90 \mathrm{v} / \mathrm{v})$ and centrifuged as described above. An internal standard, 3,4,5-trimethoxycinnamic acid, was added to the combined eluates, and the samples were analyzed using HPLC-DAD. Cytosolic fractions were thawed rapidly at $20{ }^{\circ} \mathrm{C}$ and directly mixed with $3,4,5$ trimethoxycinnamic acid and then analyzed by HPLC-DAD.

HPLC-DAD analysis was performed using an Agilent 1200 HPLC system (with column and autosampler heaters set at 30 and $4{ }^{\circ} \mathrm{C}$, respectively) equipped with a Zorbax C18 column (Agilent, Waldbronn, Germany). A 10- $\mu \mathrm{L}$ aliquot of each sample was injected and separated using a mobile phase consisting of a 60-min linear gradient of 10-50\% methanol in aqueous $0.1 \%$ formic acid with a flow rate of $1 \mathrm{~mL} /$ $\min$. Eluting phloretin and phloretin 2'-O-glucoside were detected at $280 \mathrm{~nm}$, caffeic acid, 5-caffeoylquinic acid and the internal standard at $320 \mathrm{~nm}$ and quercetin and quercetin 3-Orhamnoside at $360 \mathrm{~nm}$. The limits of quantitation (LOQs) and detection (LODs) are defined as three and ten times of the $\mathrm{S} / \mathrm{N}$ ratio (referred to [18]), ranged from 0.04 to $0.1 \mathrm{mg} / \mathrm{L}$ and from 0.02 to $0.04 \mathrm{mg} / \mathrm{L}$, respectively.

\section{Detection of Hsp90 and EEA1 Protein Expression (Western Blot Analysis)}

Digitonin-based cell fractionation was applied to Caco-2 cells to obtain cytosolic and membrane-associated fractions. Both fractions were separated by SDS-PAGE followed by western blot analysis, according to [16, 19]. The protein Hsp90 was detected with a monoclonal antiHsp90 antibody and the endosomal protein EEA1 by a polyclonal antibody.

\section{Results}

The polyphenol contents of the following three fraction types determined by HPLC-DAD are shown in Fig. 2: (i) cytosolic fractions obtained by treatment of cells with digitonin (collected in the supernatants) after 4-h incubation with apple polyphenols; (ii) membrane-associated fractions obtained by subsequent lysis of cells; and (iii) controls consisting of another set of cells lysed directly after incubation (total cell-associated fractions). Following the 4-h incubation of caffeic acid and 5caffeoylquinic acid with the cells, $0.6 \pm 0.1$ and $0.4 \pm 0.1 \%$ of the incubated hydroxycinnamic acids were detected in the cytosol fractions, respectively. In contrast, in the membraneassociated fractions, no hydroxycinnamic acids were detectable. In total cell-associated fractions, $1.0 \pm 0.0$ and $1.4 \pm$ $0.6 \%$ of the incubated hydroxycinnamic acids were found (see Table 1).

Phloretin and quercetin were present in the cytosolic fractions with $2.9 \pm 0.4$ and $2.8 \pm 0.6 \%$ of the concentrations incubated with cells and higher percentages $(8.1 \pm 1.2$ and $8.2 \pm$ $2.5 \%)$ associated with the membranes. The total cellassociated fractions showed $16.5 \pm 2.2$ and $20.3 \pm 9.2 \%$ of the incubated phloretin and quercetin, respectively.

The glycosides phloretin 2'-O-glucoside and quercetin 3$O$-rhamnoside were detected in the cytosol $(2.1 \pm 0.1$ and 0.2 $\pm 0.1 \%)$, and larger amounts $(5.2 \pm 1.8$ and $0.3 \pm 0.2 \%)$ of the initial concentrations of $50 \mu \mathrm{M}$ were associated with the membranes. Following direct lysis, $6.5+1.4$ and $1.2+0.8 \%$ of the added phloretin 2'-O-glucoside and quercetin 3-O-rhamnoside were detected in the total cell-associated fractions (Table 1).

To confirm successful separation of the cytosolic and membrane-associated fractions, discontinuous SDS-PAGE electrophoresis was performed followed by western blot analysis. The endosomal protein EEA1, a marker protein for early endosomal vesicles, and the heat shock protein Hsp90 were detected. Successful separation of the cell fractions was indicated by detection of Hsp90 in the cytosol and membrane-associated fractions, whereas the endosomal protein EEA1 was only found in the membrane-associated fraction (Fig. 3).

\section{Discussion and Conclusion}

Previous methods for analyzing the polyphenol content of cells following incubation with these compounds have 
Table 1 Cytosolic, membrane-associated, cell associated (cytosolic + membrane associated) and total cell-associated percentages of initial concentrations [\%] of apple polyphenols in T84 monolayers after a 4-h incubation

\begin{tabular}{lllrl}
\hline Compounds & Cytosolic fractions [\%] & $\begin{array}{l}\text { Membrane-associated } \\
\text { fractions [\%] }\end{array}$ & $\begin{array}{l}\text { Cell-associated [\%] } \\
\text { (cytosolic + membrane }-\end{array}$ & $\begin{array}{l}\text { Total cell-associated } \\
\text { associated fraction) }\end{array}$ \\
\hline Caffeic acid & $0.6 \pm 0.0$ & n.d. & $0.6 \pm 0.0$ & $1.0 \pm 0.0$ \\
5-Caffeoylquinic acid & $0.4 \pm 0.1$ & n.d. & $0.4 \pm 0.1$ & $1.4 \pm 0.6$ \\
Phloretin & $2.9 \pm 0.4$ & $8.1 \pm 1.2$ & $11.0 \pm 1.6$ & $16.5 \pm 2.2$ \\
Phloretin 2'-O-glucoside & $2.1 \pm 0.1$ & $5.2 \pm 1.8$ & $7.3 \pm 1.9$ & $6.5 \pm 1.4$ \\
Quercetin & $2.8 \pm 0.6$ & $8.2 \pm 2.5$ & $11.0 \pm 3.1$ & $20.3 \pm 9.2$ \\
Quercetin 3-O-rhamnoside & $0.2 \pm 0.1$ & $0.3 \pm 0.2$ & $0.5 \pm 0.3$ & $1.2 \pm 0.8$ \\
\hline
\end{tabular}

Data are mean $\pm \mathrm{SD}$ obtained from four experiments. $n . d$. Not detectable

The cytosolic contents were determined following permeation of the cells by digitonin. The membrane-associated contents were determined following lysis of the cells. The cell-associated percentages are the sum of the cytosolic and membrane-associated values. The total cell-associated contents were determined after lysis of an independent set of cells

involved lysis of intact cells and various extraction steps $[6$, 9-12, 17, 20]. The method established by Hong et al. [7] allows the separation of cytoplasmic fractions and membrane fractions after several denaturation and centrifugation steps.

However, this method is time-consuming and laborious. Hence, we tested a more rapid and convenient method to determine the cytosolic polyphenol content of cells by adapting the method reported by Kaiser et al. [15]. In this approach, incubation of cell monolayers with digitonin released cytosolic proteins within $30 \mathrm{~min}$. The polyphenol content was determined by HPLC-DAD in both cytosolic and membrane-associated fractions after 4-h incubation in

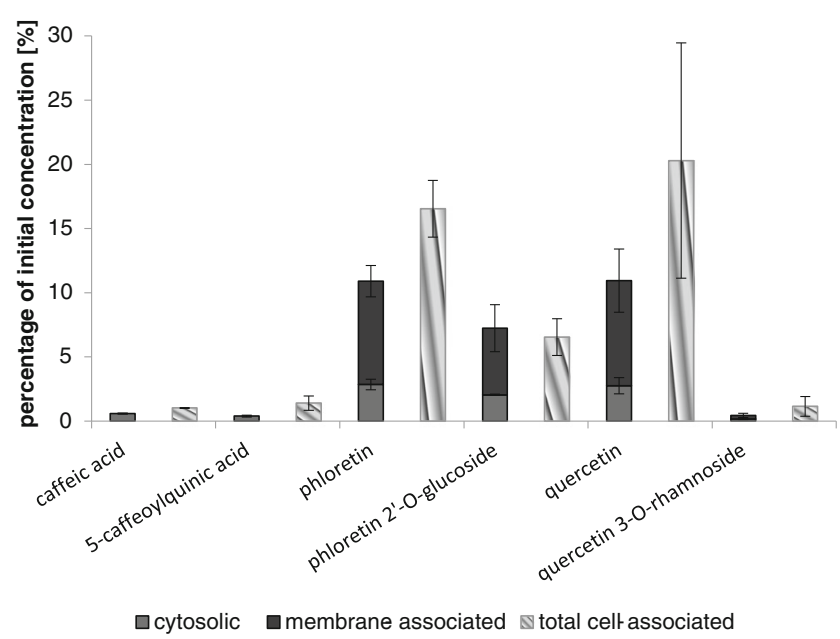

Fig. 2 Cytosolic, membrane-associated and total cell-associated percentages of initial concentrations [\%] of apple polyphenols in T84 monolayers after a 4-h incubation (initial concentration, $50 \mu \mathrm{M}$ ). The cytosolic contents were determined following permeation of the cells by digitonin, and then the membrane-associated contents were determined following lysis of the cells. Total cell-associated contents were determined after lysis of an independent set of cells. Data are mean \pm $\mathrm{SD}$ obtained from five experiments the T84 colon carcinoma cell line monolayers. The results showed that hydroxycinnamic acids (caffeic and 5caffeoylquinic acid) were solely present in the cytosol fraction; no detectable amounts of these compounds were associated with the membranes (Fig. 2). In contrast, the flavonoids phloretin, quercetin, phloretin 2'-O-glucoside, and quercetin 3-O-rhamnoside were found in the cytosol as well as membrane-associated fraction. In the cytosolic fractions, amounts of these flavonoids corresponded to 25$40 \%$ of the cell-associated fractions (cytosolic plus membrane associated). Figure 4 illustrates the distribution of phloretin in T84 cells after the 4-h incubation. These data differ slightly from those presented by Hong et al. [7], who incubated the colon carcinoma cell line HT-29 with (-)-epigallocatechin gallate, a tea flavonoid, and found that after $2 \mathrm{~h}, 67 \%$ of the cell-associated polyphenol content in the cytosolic fraction and $33 \%$ in the membrane fraction.

Our results showed that the cytosolic content of the incubated polyphenols, which were supplied in an equimolar concentration $(50 \mu \mathrm{M})$, decreased in the order phloretin $>$ quercetin $>$ phloretin $2^{\prime}$ - $O$-glucoside $>$ caffeic acid $>5$ caffeoylquinic acid $>$ quercetin 3-O-rhamnoside. The sum of the cytosolic and membrane-associated contents for

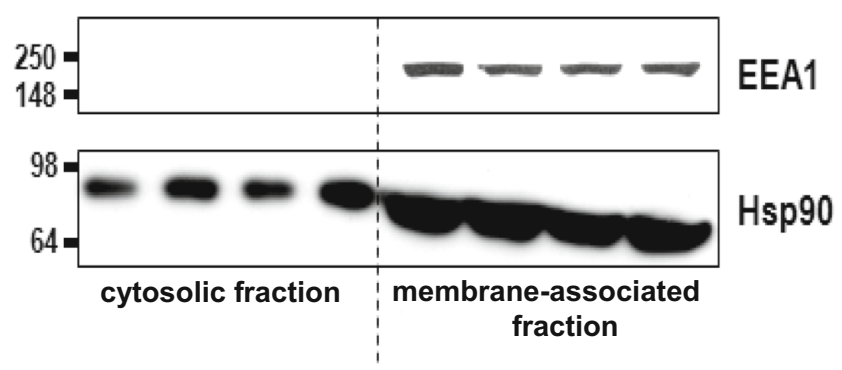

Fig. 3 Representative images of a western blot experiment of Hsp90 and EEA1 proteins in Caco-2 cells 
Fig. 4 Distribution of the dihydrochalcone phloretin in the cell membrane and cytosol of T84 cells after 4-h incubation (percentages of initial concentrations $[\%]$ )

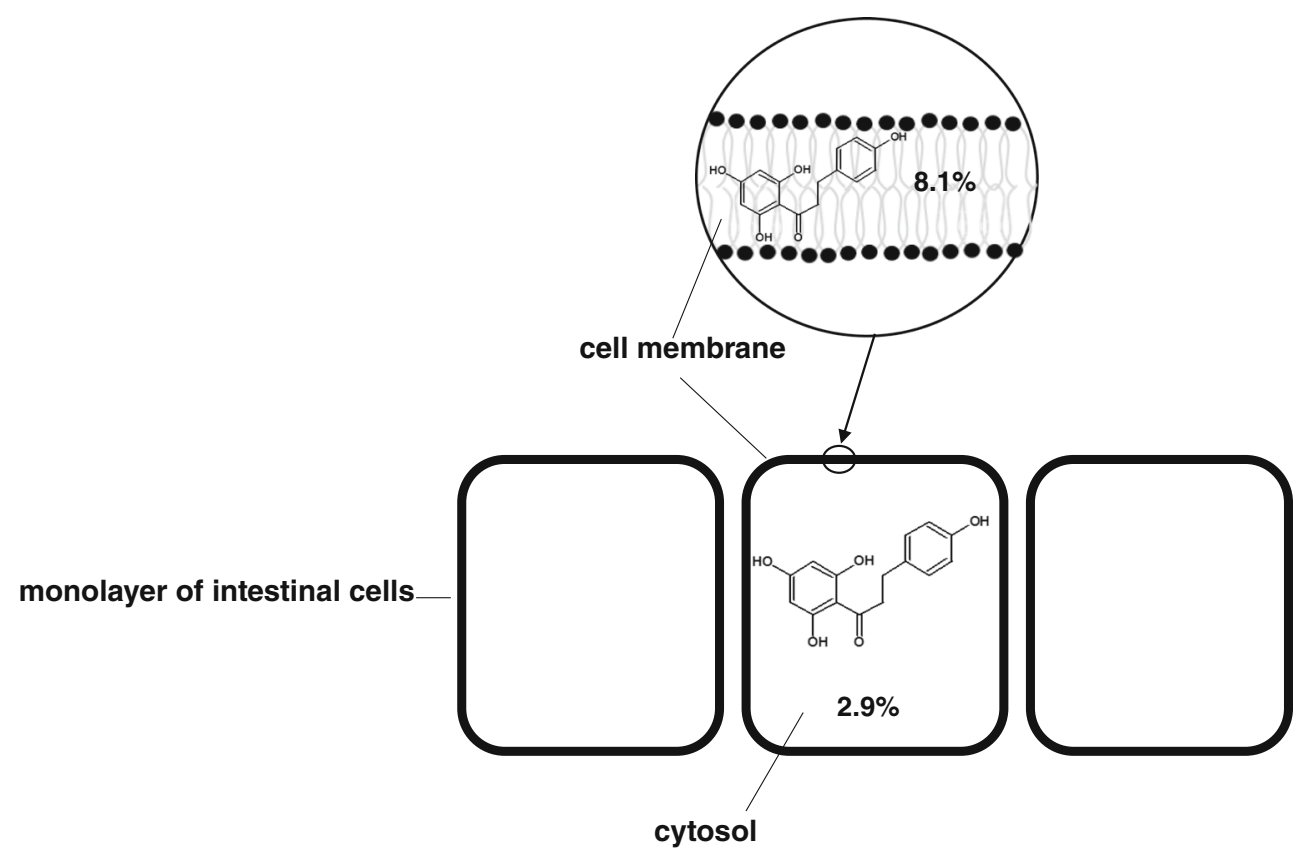

membrane, demonstrating that the cytosolic contents were completely released by this method.

Authors' Contributions HD and IG performed the incubations and analysis; TB performed cell culture, supervised the work, and wrote the manuscript; NS performed and measured the ELISA; ER planned, supervised the studies, and wrote the manuscript; and HB and EK supported the digitonin and ELISAs performed.

Funding Open Access funding enabled and organized by Projekt DEAL. The study was performed as a part of the NutritionNet project supported by the German Federal Ministry of Education and Research (BMBF), project no. 01EA0501.

\section{Compliance with Ethical Standards}

Conflict of Interest The authors declare that they have no conflict of interest.

Human and Animal Rights and Informed Consent This article does not contain any studies with human or animal subjects performed by any of the authors.

Open Access This article is licensed under a Creative Commons Attribution 4.0 International License, which permits use, sharing, adaptation, distribution and reproduction in any medium or format, as long as you give appropriate credit to the original author(s) and the source, provide a link to the Creative Commons licence, and indicate if changes were made. The images or other third party material in this article are included in the article's Creative Commons licence, unless indicated otherwise in a credit line to the material. If material is not included in the article's Creative Commons licence and your intended use is not permitted by statutory regulation or exceeds the permitted use, you will need to obtain permission directly from the copyright holder. To view a copy of this licence, visit http://creativecommons.org/licenses/by/4.0/. 


\section{References}

1. Manach C, Scalbert A, Morand C, Rémésy C, Jiménez L. Polyphenols: food sources and bioavailability. Am J Clin Nutr. 2004;79:727-47. https://doi.org/10.1093/ajcn/79.5.727.

2. Scalbert A, Johnson IT, Saltmarsh M. Polyphenols: antioxidants and beyond. Am J Clin Nutr. 2005;81:215S-7S. https://doi.org/ 10.1093/ajen/81.1.215S

3. Wojdyło A, Oszmiański J, Laskowski P. Polyphenolic compounds and antioxidant activity of new and old apple varieties. J Agric Food Chem. 2008;56:6520-30. https://doi.org/10.1021/jf800510j.

4. Boyer J, Liu RH. Apple phytochemicals and their health benefits. Nutr J. 2004;3:5. https://doi.org/10.1186/1475-2891-3-5.

5. Jedrychowski W, Maugeri U. An apple a day may hold colorectal cancer at bay: recent evidence from a case-control study. Rev Environ Health. 2009;24:59-74. https://doi.org/10.1515/reveh. 2009.24.1.59.

6. Kobayashi S, Tanabe S, Sugiyama M, Konishi Y. Transepithelial transport of hesperetin and hesperidin in intestinal caco-2 cell monolayers. Biochim Biophys Acta. 1778;2008:33-41. https:// doi.org/10.1016/j.bbamem.2007.08.020.

7. Hong J, Lu H, Meng X, Ryu J-H, Hara Y, Yang CS. Stability, cellular uptake, biotransformation, and efflux of tea polyphenol (-)-epigallocatechin-3-gallate in HT-29 human colon adenocarcinoma cells. Cancer Res. 2002;62:7241-6.

8. Vaidyanathan JB, Walle T. Cellular uptake and efflux of the tea flavonoid (-)epicatechin-3-gallate in the human intestinal cell line Caco-2. J Pharmacol Exp Ther. 2003;307:745-52. https://doi.org/ 10.1124/jpet.103.054296.

9. Ikeno A, Hashimoto K, Shimizu M, Terao J, Kumazawa S, Nakayama T. Absorption and metabolism of quercetin in caco-2 cells. FSTR. 1999;5:90-2. https://doi.org/10.3136/fstr.5.90.

10. Konishi Y. Transepithelial transport of microbial metabolites of quercetin in intestinal caco-2 cell monolayers. J Agric Food Chem. 2005;53:601-7. https://doi.org/10.1021/jf0486621.

11. Konishi Y, Kobayashi S. Microbial metabolites of ingested caffeic acid are absorbed by the monocarboxylic acid transporter (MCT) in intestinal caco-2 cell monolayers. J Agric Food Chem. 2004;52: 6418-24. https://doi.org/10.1021/jf049560y.

12. Konishi Y, Kobayashi S. Transepithelial transport of chlorogenic acid, caffeic acid, and their colonic metabolites in intestinal caco-2 cell monolayers. J Agric Food Chem. 2004;52:2518-26. https://doi. org/10.1021/jf035407c.

13. Konishi Y, Kobayashi S, SHIMIZU M. Transepithelial transport of $\mathrm{p}$ coumaric acid and gallic acid in caco-2 cell monolayers. Biosci Biotechnol Biochem. 2003;67:2317-24. https://doi.org/10.1271/bbb. 67.2317.

14. Konishi Y, SHIMIZU M. Transepithelial transport of ferulic acid by monocarboxylic acid transporter in caco-2 cell monolayers. Biosci Biotechnol Biochem. 2003;67:856-62. https://doi.org/10. 1271/bbb.67.856.

15. Kaiser E, Pust S, Kroll C, Barth H. Cyclophilin A facilitates translocation of the clostridium botulinum $\mathrm{C} 2$ toxin across membranes of acidified endosomes into the cytosol of mammalian cells. Cell Microbiol. 2009;11:780-95. https://doi.org/10.1111/j.1462-5822. 2009.01291.x.

16. Dmochewitz L, Lillich M, Kaiser E, Jennings LD, Lang AE, Buchner J, et al. Role of CypA and Hsp90 in membrane translocation mediated by anthrax protective antigen. Cell Microbiol. 2011;13:359-73. https://doi.org/10.1111/j.1462-5822.2010. 01539.x.

17. Bergmann H, Rogoll D, Scheppach W, Melcher R, Richling E. The Ussing type chamber model to study the intestinal transport and modulation of specific tight-junction genes using a colonic cell line. Mol Nutr Food Res. 2009;53:1211-25. https://doi.org/10.1002/ mnfr.200800498.

18. MacDougall D, Crummett WB, et al. Guidelines for data acquisition and data quality evaluation in environmental chemistry. Anal Chem. 1980;52:2242-9. https://doi.org/10.1021/ac50064a004.

19. Bakuradze T, Lang R, Hofmann T, Stiebitz H, Bytof G, Lantz I, et al. Antioxidant effectiveness of coffee extracts and selected constituents in cell-free systems and human colon cell lines. Mol Nutr Food Res. 2010;54:1734-43. https://doi.org/10.1002/mnfr.201000147.

20. Vaidyanathan JB, Walle T. Transport and metabolism of the tea flavonoid (-)-epicatechin by the human intestinal cell line caco-2. Pharm Res. 2001;18:1420-5. https://doi.org/10.1023/a:1012200805593.

21. Natali F, Siculella L, Salvati S, Gnoni GV. Oleic acid is a potent inhibitor of fatty acid and cholesterol synthesis in C6 glioma cells. J Lipid Res. 2007;48:1966-75. https://doi.org/10.1194/jlr.M700051JLR200.

Publisher's Note Springer Nature remains neutral with regard to jurisdictional claims in published maps and institutional affiliations. 